ESTUDIOS 


\section{LA CIUDAD DE NÁJERA EN EL TRÁNSITO DE LA EDAD MEDIA A LA MODERNA: EL CONCEJO, EL SEÑOR Y LA SOCIEDAD POLÍTICA CIUDADANA.}

por

FCO. Javier Goicolea JuLLáN

Universidad de Valladolid (Depart. de Historia Medieval)

RESUMEN: El presente trabajo de investigación sobre la ciudad de Nájera en el tránsito de la Edad Media a la Moderna, se enmarca dentro de un Proyecto de Investigación más amplio que tiene como objetito el estudio de la articulacion del poder politico en el mundo urbano de la comarca de La Rioja Alta a fines del Medievo. Un estudio que iniciamos con nuestra Tesis Doctoral sobre la villa de Haro en la centuria del cuatrocientos. En la presente investigación nos ocupamos de la ciudad de Nájera, y concretamente de su organizacion municipal, de su sociedad y de las relaciones que mantendrá este nucleo urbano riojano con sus señores, Pedro Manrique y Antonio Manrique, desde el año 1466 basta los violentos sucesor que marcarán en Nájera el tránito de la Edad Media a la Edad Moderma. Para ello vamos a utilizar una documentación que procede esencialmente de los Archivos Histórico Nacional, General de Simancas y Real Cbancillería de Valladolid.

Palabras clave: La Rioja. Nájera. Siglo XV-inicios del XVI. Municipio. Sociedad. Pedro Manrique. Antonio Manrique. Rebelión de 1520.

ABSTRACT: This work, on the town of Najera in the transitional period between the late Middle Ages and the early modern period, is pant of a broader research project aiming to stu-

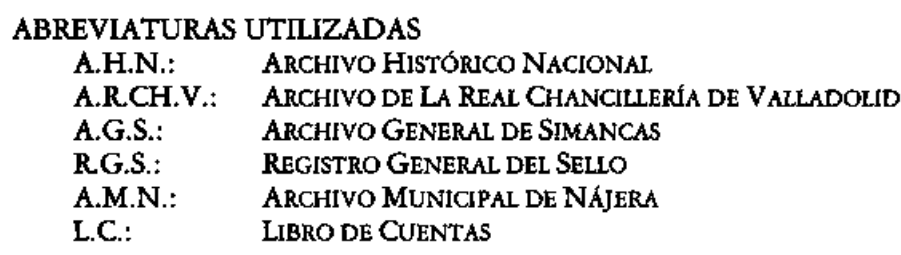


dy the organisation of political power in the towns of Upper Rioja the end of the Middle Ages. The starting point was the author's doctoral thesis on the town of Ham in the fifteenth century. The present study deals with the municipal organisation and saciety of Najera, and the relations between this toun and its noblemen Pedro Manrique and Antonio Manrique, from the year 1466 to the violent events of 1520 . This article is based mainly on bistorical dacumentation from the Arcbito Historico Nacional, General de Simancas and the Real Chancilleria de Valladolid.

Key words: La Rioja. Nájera. Municipality. Pedro Manrique. Antonio Manrique. Rebellion of 1520.

\section{INTRODUCCIón.}

La evolución política, institucional y social de los núcleos urbanos de La Rioja Alta a finales de la Edad Media e inicios de la Edad Moderna, presenta todavía bastantes interrogantes ${ }^{1}$. En efecto, si exceptuamos los estudios sobre la ciudad realenga de Logroño, a los que ya haremos referencia en el transcurso de este trabajo, el resto del mundo urbano altorriojano ha sido un gran desconocido hasta hace poco tiempo, especialmente en lo referente a aquellas ciudades y villas que a lo largo de la Edad Media quedaron sometidas a jurisdicciones señoriales². Una de estas ciudades que se integró a finales de la Edad Media en un dominio señorial, concretamente en el dominio señorial del linaje Mantique, fue Nájera, a cuyo estudio se dedican las siguientes páginas.

Desde el siglo $X$ y a lo largo del XI Nájera experimentó un destacado desarrollo en el contexto del territorio riojano, convirtiéndose en un importante centro político, cultural y económico, al trasladar los reyes de Pamplona a este núcleo de población la dirección política del Reino ${ }^{3}$. En el año 1076, coincidiendo con el inicio de la dominación del territorio riojano por parte de los reyes castellanos y con el apogeo del Camino de Santiago, la villa tecibió fueto

\footnotetext{
' Algunas interesantes reflexiones sobre la evolución histórica de La Rioja Alta en la Edad Media e inicios de la Edad Moderna, pueden verse en (GARCía DE CORTÁZAR, José Ángel: «Introducción al estudio de la sociedad altoriojana en los siglos X al XIV", Berreo, $\mathrm{n}^{\circ} 88$ (1975), pp. 3-29 y Gómez URDÁN̄EZ, José Luis: «La Rioja a comienzos de la Edad Moderna", Brocar, nº 18 (1994), pp. 139-188).

' A la villa de Haro a finales de la Edad Media he dedicado mi Tesis Doctoral titulada: La sociedad altorriojana a finates de la Edad Media: el ejemplo de la villa de Haro y sus aldeas (s. XV). Una parte importante de este trabajo se recoge en mi libro Haro: una villa riojana del linaje Velasco a fines del Medievo, Logroño, 1999. En la actualidad estoy desarrollando un Proyecto de Investigación sobre el mundo urbano altorriojano a finales de la Edad Media, gracias a una Beca Postdoctoral concedida por el Departamento de Educación, Universidades e Investigación del Gobierno Vasco.

${ }^{3}$ Fernández de la Pradilla Mayoral, M². Concepción: El reino de Nájera (1035-1076). Población, economia, sociedad y poder, Logron̄o, 1991.
} 
del monarca Alfonso VÍ. Será el comienzo de un importante desarrollo artesanal y, comercial, incentivado por la concesión de privilegios por parte del poder real, y con el que culminará la conformación urbanística de Nájeras.

En los años centrales de la Edad Media, especialmente desde mediados del siglo XIII (reinado de Alfonso X), la organización político-social de Nájera junto a la del resto de las villas riojanas, sufrió importantes transformaciones. De esta forma, las relaciones de Nájera con su tertitorio y con el poder teal, la sociedad urbana y las expectativas económicas de la villa, experimentaron profundos cambios en relación al período anterior ${ }^{6}$. Pero los años finales del siglo XIII marcan también el comienzo de importantes dificultades en la villa, plasmadas en la crisis por la que atravesaba el monasterio de Santa María la Real, ya desde las primeras décadas de esta centuria ${ }^{7}$. La recesión continuará a lo largo del XIV, y únicamente a finales de este siglo se advierten indicios de una cierta recuperación, que se verá confirmada en la centuria del cuatrocientos ${ }^{8}$.

Nuestra investigación se va a centrar en el siglo XV, especialmente en sus años finales y en las primeras décadas del siglo XVI. No es la primera vez que dirigimos la atención hacia Nájera y en concreto hacia este período de tiempo. En efecto, en investigaciones anteriores hemos estudiado su hacienda concejil a través de los Libros de cuentas que se han conservado en el Archivo Municipal para la centuria del cuatrocientos 9 . En esta ocasión nos vamos a ocupar de la

${ }^{4}$ Martínez Díkz, Gonzalo: "Los fueros de la Rioja», Anuario de Historia del Derecho Españal, $n^{\circ}$ XIIV (1979), pp. 327-455, especialmente pp. 404-411.

s García de Cortázar, Joś Ángel: «Otganización social del espacio en La Rioja cristiana en los siglos X y XI», Historia de la ciudad de Logroño, Logroño, 1995, vol n ${ }^{\circ}$ II (Edad Media, SESMA MuÑOZ, Miguel Ángel, Coord.), pp. 53-168, especialmente pp. 156-161, RUIZ DE LA PEÑA, Juan Ignacio: «La formación de la red urbana en el tramo riojano del Camino de Santiago y las colonizaciones francas (siglos XI-XIII)", Actas de la Reunión Científica «El Fuero de Logroño y su época», Logroño, 1996, pp. 21 1-230, MOYa VALGAÑón, José Gabriel: «Documentos medievales del Archivo Municipal de Nájeras, Cuadernos de Invertigación Histórica (Brocar), no VI (1980-82), pp. 55-71, GONZÁleZ MíNGUEZ, César: "Notas sobre la exención de portazgo de Nájera», Cuadernos de lnvestigación Histérica (Brocar), $\mathrm{n}^{\circ}$ IX, fascículo 2 (1983), pp. 39-46, CANTERA MONTENEGRO, Enrique: «Franquicias regias a ciudades y villas riojanas en el marco de la política repobladora de Alfonso X", Berceo, $0^{\circ}$ 114-115 (1988), pp. 105-118, García TurZA, Fco. Javier: «Morfología de la ciudad de Nájera en la Edad Median, Actas de la III Semana de Estudios Medievales (Nájera, del 3 al 7 de agosto de 1992), Logroño, 1993, pp. 63-88, PASSINI, Jean «El Camino de Santiago en La Rioja: trazados y núcleos", Actas de la IV Semana de Estudios Medievales (Nájera del 2 al 6 de agosto de 1993), Logroño, 1994, pp. 121-133).

6 MARTíneZ SOPENA, Pascual: «Logroño y las villas riojanas entre los siglos XII al XIV», Historia de la ciudad de Logroño..., o.c., pp. 279-322.

7 Garcia TURzA, Fco. Javier: «Morfología de la ciudad de Nájera..., o.c., pp. 63-88, especialmente pp. $77-78$.

8 Ibidem., especialmente pp. 78-80.

9 GoICOLEA JuIIÁN, FCo. Javier: «Las finanzas concejiles y la fiscalidad de Nájera en la segunda mitad del siglo XV. El ejercicio del bolsero Martín Romero (1476-1477)», Espacio, Tiempo y Forma, $\mathrm{H}^{\mathrm{a}}$. 
organización concejil y de la sociedad de Nájera a finales de la Edad Media e inicios de la Moderna. Igualmente estudiaremos las conflictivas relaciones que se van a plantear entre Nájera y sus señores, pues no debemos olvidar que en la segunda mitad del siglo XV la ciudad se integró en el dominio señorial del linaje Manrique ${ }^{10}$. Para todo ello nos valdremos de la documentación sobre la ciudad de Nájera que se conserva en los Archivos Nacionales; concretamente en los Archivos General de Simancas, Real Chancillería de Valladolid y Archivo Histórico Nacional, así como de algunos documentos del Archivo Municipal.

\section{NÁJERA EN EL SIGLO XV: UN NÚCLEO URBANO AMBICIONADO POR LA NO- BLEZA.}

La centuria del cuatrocientos es también un período inestable y conflictivo para Nájera, pues la ciudad sufrirá las consecuencias del enfrentamiento entre los linajes Manrique y Estúñiga, que trataban de someter a su control a este importante núcleo urbano perteneciente al realengo. De esta forma, sabemos que el obispo don Diego de Estúñiga llegó a apoderarse de la fortaleza de Nájera hacia el año 1440, construyendo en ella una casa fuerte desde la que guerreaba contra el adelantado Diego Manrique ${ }^{11}$. Durante el tiempo que don Diego de Estúñiga estuvo apoderado de Nájera, que se prolongó hasta su muerte, los vecinos de la ciudad sufrirán las consecuencias de los abusos ejercidos por él y por su sobrino y sucesor: Iñigo Ortiz de Estúñiga ${ }^{12}$. Este último siguió guerreando con Diego Gómez Manrique, hasta que el adelantado consiguió entrar en la ciudad y cercarle en la fortaleza' ${ }^{13}$.

En el curso de estos acontecimientos bélicos, Diego Gómez Manrique llegará a apoderarse de Nájera, aunque será expulsado de la ciudad en el mismo año de 1451 por el príncipe y futuro rey Enrique IV. En el asalto fue saqueado

Medieval, $\mathbf{n}^{\circ} 9$ (1996), pp. 119-135 y «Finanzas concejiles en la Castilla Medieval: el ejemplo de La Rioja Alta (siglo XV-inicios del XVI)», Brosar $\mathrm{n}^{\circ} 22$ (1998), pp. 21-50.

io Montero Tejada, Rosa María: «Los señoríos de los Manrique en la baja Edad Median, Espacio, Tiempo y Foma, $\mathrm{H}^{\mathrm{a}}$. Medieval, $\mathrm{n}^{\circ} 7$ (1994), pp. 205-258.

11 «que la tomo el obispo don Diego, y tomo la Mota de esta dicha ciudad, e hizo la casa fuerte que en ella esta, y dende hizo guerra al adelantado Diego Manrique» (A.H.N.: NOBLEZA, Osuna, leg. 296, $n^{\circ}$ I (1), fol. 13).

12 Diago Hernando, Máximo: aLinajes navarros en la vida política de la Rioja bajomedieval. El ejemplo de los Estúñigas, Principe de Viano, $\mathrm{n}^{\circ} 197$ (1992), pp. 563-581, especialmente pp. 570571. En el memorial del pleito entre el concejo de Nájera y los Manrique, se hace referencia a que en 1450 Iñigo Ortiz de Estúñiga era alcalde en Nájera, su tierra y merindad, por el Rey (A.H.N.: NoBlezA, Osuna, leg. 296, $\mathrm{n}^{\circ} 1$ (1), fol. 79).

13 ey despues que sucedio en la dicha ciudad y fortaleza el capitan Yñigo de Zuñiga y la tuvo gran tiempo y huvo guerra con el adelantado don Diego Gomez Manrique, y entro en la ciudad y cerco al dicho capiran y tuvieron guerra el uno con el otron (A.H.N.: NoblezA, Osuna, leg. 296, $\mathrm{n}^{\circ}$ 1 (1), fol. 13). 
el monasterio de Santa María la Real, y en compensación el príncipe le hizo merced de tres mil maravedís de juro sobre las alcabalas del vino de la ciudad ${ }^{14}$. Enrique IV concedió igualmente varios privilegios a Nájera, favoreciendo su poblamiento, asegurando su defensa y guarda para la Corona real, e impidiendo el avecindamiento en ella de caballeros y hombres poderosos, mediante un privilegio fechado en $1458^{15}$.

No por ello finalizaron las presiones de la nobleza, especialmente del linaje Manrique, pues el II conde de Treviño, Pedro Manrique, hijo del conde don Diego, atacó nuevamente Nájera en 1463 y 1464. Algunos de los capítulos del gasto concejil asentados por los bolseros de estos años, dejan constancia de los hechos acontecidos en la ciudad. Entre otras partidas del gasto se incluyen algunas relativas al envío de mensajeros para espiar los movimientos de la tropa del conde de Treviño, reforzamiento de los elementos defensivos de la ciudad: cavas, caramanchones, palenques, etc. o la realización de vigilancias en la fortaleza o Mota y en la muralla. En todas estas actividades participaron los vecinos de Nájera organizados en cuadrillas, así como los vecinos de la aldea de Tricio, que fueron socorridos de forma decisiva por Diego López de Estúñiga, Pedro Ruiz de Ahumada y por el señor de Ezcaray en la defensa de la ciudad ${ }^{16}$.

No obstante, un año después, en 1465, el monarca Enrique IV accederá a las pretensiones del conde de Treviño, concediéndole la ciudad de Nájera en reconocimiento a su fidelidad frente al resto del linaje Manrique, que apoyaba el partido del infante don Alfonso ${ }^{17}$. La entrada de Pedro Manrique en la ciudad no fue, sin embargo, fácil. En efecto, los vecinos de Nájera se negaron a aceptar al conde de Treviño como señor, lo que dio lugar al asedio y toma de la ciudad por las tropas de Pedro Manrique en 1466: «que el dicbo duque vino a

14 "por razon del danno que el dicho monasterio recibio quando el dicho principe fue a la dicha ciudad y prendio al dicho conde don Diego, le haze merced al dicho monasterio de tres mil maravedis de juro sobre las alcavalas del vino de la dicha ciudad" (A.H.N.: NoblezA, Osuna, leg. 296, $\mathrm{n}^{\circ}$ 1 (1), fol. 14).

is «manda que sin su licencia y especial mandado no dexen ni consientan entrar ni entren en la dicha ciudad ni se avezindar ni fazer asiento a cavallero ni persona alguna que de ella se pueda apoderat, salvo solamente si fuere de passada× (A.H.N.: NOBLEZA, Osuna, leg. 296, $\mathrm{n}^{\circ} 1$ (1), fol. 10).

16 uvinieron en socorro de la ciudad Pedro Manrique y Diego Lopez de Stuniga y Pedro Ruiz de Aumada, mandaronles dar raciones a yantar y cenar a cien hombres.... (A.H.N.: NoblezA, Osuna, leg. 296, $\mathrm{n}^{\circ}$ I (1), fol. 16).

17 «y ansi mismo los muchos y buenos y leales y sennalados servicios que vos don Pedro Manrique Conde de Trevinno mi vasallo y del mi Consejo me avedes fecho y fazedes de cada dia y fizieron aquellos donde vos venides a los Reyes de gloriosa memoria mis progenitores, y en alguna encomienda y remuneracion de ellos por la presente vos fago merced, gracia y donacion pura y propia y noa revocable por juro de heredad para siempre jamas de la Ciudad de Najera con su Castillo y fortaleza y con todos los lugares de su tierra y con todo su termino y distrito y termino y jurisdicion». La donación está fechada en el Real cerca de Toro el 30 de julio de 1465 (A.H.N.: NOBLEZA, Osuna, leg. 296, $\mathrm{n}^{\circ} 1$ (1), fols. 102-105 y MONTERo TejadA, Rosa María: «Los señoríos de los Manrique..., o.c., p. 212). 
tomar la dicha ciudad y todos los otros dichos bienes diziendo que el dicho sennor rey don Enrique le avia becho merced de todos los dichos bienes, y porque a causa que la dicha ciudad no se le quiso dar ni entregar, que vido que el dicho duque puso cerco sobre la fortaleza de la dicba ciudad contra los vezinos de la dicha ciudad que en ella se retraxeron y estaban, y que los tuvo alli cercados mucho tiempo asta tanto que se le dieron, y el dicho duque la tomo y gano todo de esta manera, y que lo sabe asi mismo el testigo porque se ballo y estuvo en la dicba fortaleza de la dicha ciudad estando cercada por el dicbo duque, y aun porque al dicho tiempo sobre el dicho cerco le mataron al testigo un bermano peleando en la defensa de la dicha fortaleza y ciudad de Nagera contra el dicbo duque» ${ }^{18}$.

Posteriormente, y en recompensa al apoyo prestado por el conde de Treviño a Isabel y Fernando en la sucesión al trono, los Reyes Católicos confirmarán a Pedro Manrique en el señorío sobre Nájera (16-VII-1476), instando a los oficiales del concejo a acatar la autoridad señorial como "buenos vasallos» ${ }^{19}$. Una confirmación que volverán a repetir en 1482 , dando además facultad a Pedro Manrique para incorporar la ciudad a su mayorazgo (21-IV-1482) ${ }^{20}$ y otorgándole así mismo el título de duque de Nájera (30-VIII-1482), que ostentarán él y sus sucesores a partir de esta fecha ${ }^{21}$.

\section{GOBIERNO URBANO Y SOCXEDAD EN LA DÉCADA DEL CUATROCIENTOS.}

Tal y como ha puesto de relieve recientemente el profesor Pascual Martínez Sopena, el binomio alcaldes-jurados caracterizó la organización concejil de los núcleos urbanos riojanos desde mediados del siglo XIII, subsistiendo todavía este esquema de gobierno en los años centrales de la centuria del trescientos ${ }^{22}$. Con respecto al caso concreto de Nájera, también se constata esta situación, y en efecto documentamos al frente de su concejo a jurados y a dos alcaldes encargados de impartir justicia ${ }^{23}$. Bastante más difícil resulta, sin embargo, precisar qué sucedió a partir de la reforma municipal llevada a cabo en el reinado de

\footnotetext{
is Testimonio del vecino de Nájera Juan del Castillo. Alonso de Lampaya, vasallo de Pedro Manrique, del cual recibió acostamiento y participó a su lado en la toma de Nájera, también se refiere a estos sucesos acaecidos en 1466 uque fue con el a lo tomar y ganar porque al dicho tiempo este testigo vivia con el dicho duque don Pedro y se hallo con el en los cercos y toma que hizo de la dicha ciudad» (A.H.N.: NOBLEZA, Osuna, leg. 296, $\mathrm{n}^{\circ} 1$ (1), fols. 18 y 19).

19 A.H.N.: NOBLEZA, Osuna, leg. 296, $\mathrm{n}^{\circ} 1$ (1), fol. 17 (2 $2^{\circ}$ memorial). Sobre la participación de Pedro Manrique en los sucesos políticos y militares acontecidos tras la muerte de Entique IV y la lucha por la sucesión al trono, me remito a (SUÁREZ FERNANDEZ, Luis y MATA CARRIAZO ARROQUIA, Juan de: La España de los Reyes Católicos (I), en Historia de España dirigida por Ramón Menéndez Pidal, vol. XVU, Madrid, 1983 ( $3^{\mathrm{a}}$ edición).

${ }^{20}$ A.H.N.: NOBLEZA, Osuna, leg. $296, \mathbf{n}^{\circ} 1$ (1), fols. 52-54.

21 MONTERo TEjadA, Rosa María: «Los señoríos de los Manrique..., o.c., pp. 212-213.

22 MARTINEZ SOPENA, Pascual: «Logroño y las villas riojanas entre los siglos XII al XIV toria de la ciudad de Logroño..., o.c., pp. 304.

${ }^{23}$ Ibidem., Pp. 303-304.

Hispania, LX/2, núm. $205(2000) 425-452$
} 
Alfonso XI (creación del Regimiento), y en este sentido desconocemos cuando se introdujo la figura del regidor en el concejo de Nájera ${ }^{24}$.

Es ya en el siglo XV, concretamente en 1439 , cuando constatamos por primera vez la presencia de regidores. Son cuatro regidores que ejercen sus funciones junto a los dos alcaldes tradicionales: «que fueron alcaldes este dicho anno en la çibdad de Najera Diego Lopes de Labastida e Diego Peres e regidores Diego Gonçales bachiller e Diego Martines de Grannon e Juan de Sant Juan e Juan Peres Valgannon», y que como el resto de oficiales concejiles eran elegidos el día de San Martín de noviembre ${ }^{25}$.

A lo largo de la primera mitad del siglo XV se mantendrá el número de regidores y alcaldes ordinarios en la organización concejil de Nájera, complementándose el listado de oficiales municipales del año 1456 con un bolsero, un escribano de cámara, un procurador del concejo, un letrado asesor, cuatro jurados, dos fieles, dos apreciadores y cuatro custieros o guardas de los términos. Todos estos oficios concejiles eran de renovación anual, mediante un proceso electivo en el que participaba la sociedad política local: los miembros del Regimiento y también otros omes buenos de la ciudad, como parece desprenderse de las Actas de elección de oficios que se han conservado ${ }^{26}$.

En la segunda mitad del siglo XV se sigue manteniendo el mismo esquema de oficios municipales renovados anualmente, aunque ampliado con un administrador de la casa de San Lázaro y otro del Hospital ${ }^{27}$. En lo referente a las sesiones y reuniones concejiles, como ocurre en general en el mundo urbano bajomedieval altorriojano, el concejo de Nájera mantenía un carácter abierto a lo largo del siglo XV, aunque las sesiones de concejo amplio se complementaban con otras sesiones más restringidas, en las que los miembros del Regimiento debatían y decidian las líneas políticas a seguir por la ciudad. En cuanto a las

\footnotetext{
24 Sobre la implantación del Regimiento y sus consecuencias sociales pueden verse los trabajos de (MONSAlvo ANTÓN, José María: «La sociedad política en los concejos cascellanos de la Meseta durante la época del tégimen Medieval. La distribución social del podert, Actas del II Congreso de Estudios Medievales: Concejos y Cizdades en la Edad Media Hispánica, Madrid, 1990, pp. 357-415 y VAL. Valdivieso, María Isabel del: "Oligarquía versus común (Consecuencias sociopolíticas del triunfo del regimiento en las ciudades castellanas)", Medievalismo, $\mathrm{n}^{\circ} 4$ (1994), pp. 41-58). Sobre la sociedad urbana castellana del siglo XV me remito al trabajo de (LADERO QUESADA, Miguel Ángel: "Corona y ciudades en la Castilla del siglo XV", En la España Medieval, no 5 (1986), pp. 551-574).

25 A.M.N.: L.C. 1439-40.

26 «Estando todos a son de canpana tanyda segund costunbre en la sobre claustra del monasterio de Santa Maria de la dicha çibdat en espeçial el bachiller Pero Ferrandes e Gil Garçia de Ubago alcaldes de este anno de çinquenta e çinco e Ruy Martines e Diego Sanches de la Puente e Lope Gonçales de Leyba e Alfonso Ferrandes de Santo Domingo regidores e otros asas buenos omes de la dicha çibdat en espeçial Diego Gonçales e Martin Peres bachilleres e Diego Lopes de Labastida e Diega Martines de Aleson e Pero Martines cavallero e otros asas, los quales en presençia del dicho conçeio nonbraron por alcaldes e regidores..." (A.M.N.: L.C. 1455-56, Actas de elección de oficios insertas).
}

27 A.M.N.: LC. 1476-77, Actas de elección de oficios insertas. 
primeras, sabemos que sus reuniones se celebraban en recintos amplios como la «sobre claustra" del monasterio de Santa María la Real o incluso en lugares abiertos como la Puerta nueva ${ }^{28}$. En lo referente a las sesiones restringidas, en 1439 se utilizaba como lugar de reunión la cámara de la cofradía de San Juan²9.

Las novedades en el organigrama del gobierno urbano vendrán motivadas como consecuencia de la consolidación en la ciudad del poder señorial del linaje Mantique (duques de Nájera a partir de 1482), que hacia la segunda mitad de la década de los ochenta comenzarán a intervenir en el nombramiento de oficiales concejiles y colocarán al frente del gobierno de la ciudad a un representante señorial que ostentará las más altas atribuciones y responsabilidades ejecutivas, así como la justicia, desplazando de esta manera a los tradicionales alcaldes ordinarios: "que syendo la juresdiçion çibil y criminal de la dicha ģibdad y su tierra e merindad del conçeio de la dicha çibdad pertenesçiendo por prebilegios de los reys de gloriosa memoria vuestros progenitores, aviendola el dicho conçeio usado y exercido por sus alcaldes por tienpo inmemorial, de algunos annos aca los duques la an bosurpadow ${ }^{30}$. El primer representante permanente de la justicia señorial del linaje Manrique que documentamos en la ciudad es el doctor Alonso Hernández de la Peña y Moneo, en 1488, 1489, 1492 y $1493^{31}$. Se le denomina corregidor y estaba auxi-

${ }^{28}$ A.M.N.: L.C. 1455-56, asientos del 18 y 30 de noviembre de 1455 .

29 «Este dia conpre por mandado de los alcaldes e buenos ommes dos cargas de heno para la camara de la cofradia de Sant Juan donde fasen su ayuntamienton (A.M.N.: L.C.: 1439-40, cuenta de gastos, asiento del 23 de noviembre de 1439).

${ }^{30}$ A.G.S.: Cámara de Castilla, Memoriales, leg. 130, docs. $n^{\circ} 61$ y n ${ }^{\circ} 62$. En el memorial del pleito que enfrentaba al concejo de Najera con los Manrique, se hace referencia a que "por los annos pasados, cercanos de 1490, aviendo antes justiçias puestas por la ciudad en nombre de su Magestad que exercian la jurisdicion civil y criminal, con la misma fuerça y violencia se las quito y puso de su mano, despojandoles de hecho de ella» (A.H.N.: NobrezA, Osuna, leg. 296, $\mathrm{n}^{\circ} 1$ (1), fol. 81). Sin embargo, lo cierto es que en el documento de donación de 1465 , se especificaba que el ejercicio de la juscicia civil y criminal en la ciudad así como los dernás oficios pertenecerían a la autoridad señorial: «os ayan e reciban por sennor de la dicha Ciudad y su tierra y vos fagan juramento y pleyro omenage que en tal caso se requiere y toda reverencia y obediencia que como a sennor de la dicha Ciudad y su tierra vos es devida y cumplan vuestras cartas y mandamientos y vos dexen y consientan libremente a vos y a los que de vos en los dichos oficios de la iusticia y de los ottos oficios de la dicha Ciudad y su tierra pusieredes en vuestro lugar los usar y exercer ansi en lo civil como en lo criminal y cumplir y executar en ella e en su termino la mi iusticia e aver e llevar los derechos a ella pertenecientes» (A.H.N.: NOBLEZA, Osuna, leg. 296, $\mathrm{n}^{\circ} 1$ (1), fol. 103).

3) A.G.S.: RG.S., fol. 84 (1-II-1488), Consejo Real, leg. 71, A.R.CH.V.: Pleitos Civiles, escribanía de Alonso R (F), C. 2796-4, A.H.N.: Clero, carp. 1039, $0^{\circ}$ 3. Sobre las relaciones de concejos urbanos con sus señores pueden verse los trabajos de (MONSALvo ANTón, José María: El sistema politico concejil. El ejemplo del señorío medieval de Alba de Tormes $y$ su concejo de villa y tierra, Salamanca, 1988, EstreBan ReClo, María Asunción: Palencia a fines de la Edad Media. Una ciudad de señorío episcopal, Valladolid, 1989, MARTín CEA, Juan Carlos: El mundo rural castellano a fines de la Edad Media. El ejemplo de Paredes de Nava en el siglo XV, Valladolid, 1991, LóPEZ CARrEIRA, Anselmo: $A$ cidade de Ourense no século XV. Sociedade urbana na Galicia baixomedieval, Ourense, 1998, BECEIro PITA, Isabel: El Condado de Benatente en el siglo XV, Salamanca, 1998, Olmos HeRGUEDAS, Emilio: La comunidad 
liado en sus funciones por un teniente de corregidor, vecino de la ciudad. No obstante, como ya veremos más adelante, será con la llegada al corregimiento de Rodrigo de Alfaro, cuando la tensión entre la ciudad y su señor aumente de forma alarmante.

Desde el punto de vista de las características de la sociedad política local a finales de la Edad Media, sabemos que al igual que ocurría en otras ciudades riojanas tales como Logroño ${ }^{32}$ o Calahorra ${ }^{33}$, también en Nájera la sociedad estaba dividida en «estados» o estamentos. Concretamente en Nájera existían como en Logroño tres «estados» que agrupaban a los bijosdalgo, a los ciudadanos-ruanos y a los labradores de la ciudad. En cuanto a la composición social de estos «estados", la pequeña nobleza estaba conformada por hidalgos de «solar conocido» que basaban su poder económico esencialmente en las rentas de la tierra y su prestigio en su función militar (mantenían caballo y armas), y algunos de ellos, como Gauna, que será ahorcado en el levantamiento antiseñorial de 1520, estaban vinculados también al servicio de los duques. Junto a éstos, pero con un nivel económico y de prestigio bastante inferior, se situaban los hidalgos de privilegio, que a lo largo de la centuria del cuatrocientos tratarán de asimilarse a los primeros ${ }^{34}$.

Frente a la pequeña nobleza se encontraban los pecheros, divididos en dos estamentos. Por un lado, los ciudadanos-ruanos, que integraban en su seno a vecinos dedicados a actividades artesanales y comerciales, destacándose a la cabeza de este estamento personajes de gran prestigio social, entiquecidos con el comercio y con otras actividades no ligadas al trabajo directo de la tierra: «que en la dicha ciudad de Nagera que ba seydo uso y costunbre de sacar por regidores de ella de los que llaman çiudadanos $y$ ruanos en cada un anno los mas bonrrados $y$ prençipales del pueblo, y sienpre de contino save y a bisto que los que beran mas bonrrados y prencipales de la dicba ģiudad se an llamado y llamaban giiudadanos y ruanos, porque los que asi se an llamado ģiudadanos y ruanos a bisto que an bibido e bibian de sus bagiendas $y$ tratos sin andar al canpo a travajar, $y$ se andavan paseando por las

de villa y tierra de Cuellar a finer de La Edad Media, Valladolid, 1998, GoicolEA JULIÁN, FCo Javier: Haro: una villa riojana del linaje Velasco..., o.c.).

32 En esta ciudad se documenta una división estamental conformada por hidalgos, ciudanos y labradores (Diago Hernando, Máximo: «Conflictos estamentales por el control del gobiemo municipal en Logroño a fines del XV y principios del XVI, Cuadernos de Estudios Medievales y Cienciass $y$ Técnicas Historiográficas, $\mathrm{n}^{\circ} 17$ (1992), pp. 205-225).

${ }_{33}$ En un documento del año 1515 se hace referencia a que la sociedad política de esta ciudad estaba estructurada en dos «estados»: hidalgos y pecheros-ciudadanos (A.G.S.: Cámara de Castilla, Pueblos, leg. S, doc. $n^{\circ} 24$ (4)).

${ }^{34}$ Por ejemplo, sabemos que el vecino de la aldea de Tricio, Ferrand Pérez, recibió privilegio de hidalguía del monarca Enrique IV por «los buenos y leales serviçios que me avedes fecho" (A.RCH.V.: Pleiros Civiles, escribanía de Lapuerta (F), C. 2546-3). 
calles $y$ ruas de la dicha çiudad y a esta cavsa a bisto que se an llamado ģiudadanos $y$ ruanoss 35 .

Disponemos de algunos datos sobre dos familias de ciudadanos-ruanos vinculadas al poder concejil y a los duques a fines de la Edad Media. La primera de ellas es la familia Salinas. El primero de sus miembros que constatamos es Juan de Salinas, hermano del platero Diego de Salinas. Juan de Salinas fue alcalde en 1464, y posteriormente alcaide hasta $1479^{36}$, año en que redactó su testamento «estando doliente en cama» en la ciudad de Nájera ${ }^{37}$. Vinculado a Pedro Manrique, había recibido diversas mercedes por parte del poder real, como el cobro «por juro de beredad» de varios miles de maravedís anuales procedentes de las alcabalas de la ciudad de Logroño ${ }^{38}$, y así mismo el monarca Enrique IV le había hecho merced en 1465 de las rentas del portazgo y martiniega que se recaudaban en Nájera ${ }^{39}$. Derechos que había intercambiado con su señor Pedro Manrique por una suma de varios miles de maravedís, provenientes de las rentas que la autoridad señorial recaudaba en la villa de Navarrete ${ }^{40}$. Posteriormente distinguimos como regidores en Nájera a sus hijos Diego de Salinas, en 1503, y Pedro de Salinas, en 1512 y $1516^{41}$, mientras otro de los hijos del alcaide, también llamado Juan, fue procurador y secretario de Pedro Manrique. Finalmente, también documentamos a un Martín de Salinas como "contino» del duque en $1514^{42}$.

La otra familia de ciudadanos-ruanos son los Belorado, procedentes de la villa burgalesa del mismo nombre. Sabemos que a fines del siglo XV Alonso González de Belorado eque fue persona muy bonrada y rico y cavdaloso y de los prin-

${ }^{35}$ A.R.CH.V.: Pleitos Civiles, escribanía de A. Rodríguez (F), C. 1020-1. El estamento de los ciudadanos, conformado por comerciantes y hombres de negocios, también va a desempeñar un importante papel político en el concejo de la ciudad de Logroño a fines de la Edad Media (Dusco HERNANDO, Máximo: «Conflictos estamentales por el control del gobierno municipal en Logroก̃o..., o.c., pp. 205-225).

${ }^{36}$ A.H.N.: Clero, carp. 1038, n $^{\circ} 17$ y A.G.S.: R.G.S., fol. 111 (12-XII-1487)

37 A.H.N.: Clero, carp. 1038, $\mathrm{n}^{0}$ 12. El testamento puede verse en (ENRÍQuez FERNÁNDEZ, Javier y OTROs: Colección Documental de los monasterios de Santo Domingo de Lequeitio (1289-1520) y Santa Ana de Elorrio (1480-1520), Fuentes docuraentales medievales del País Vasco, Donostia, 1993, doc. $\mathrm{n}^{\circ}$ 50, pp. 105-116). En una de las mandas testamentarias, Juan de Salinas dejaba a su hermano el platero Diego de Salinas alas casas del canton en que al presente tiene la tienda, despues de los dias de mi madre, este porque ella ha de vivir en ellas en su vidas.

34 ENRíqueZ Fernández, Javier y OTRos: Colección Documental de los monasterios..., o.c., doc. $\mathrm{n}^{0}$ 50, pp. 105-116.

39 A.H.N.: NOBLEZA, Osuna, leg. 296, $\mathrm{n}^{\circ} \mathrm{l}$ (1), fol. 90. En el ejercicio 1476-77, los cogedores de la martiniega edieron a Juan de Salinas dos mill e seinçientos maravedis que monta la cabeça de la martiniega por merçed que el tiene del rey" (GolColes JULLAN, Fco. Javier: «Las finanzas concejiles y la fiscalidad de Nájera..., o.c., p. 130).

40 A.H.N.: NOBleZA, Osuna, leg. 296, $\mathbf{n}^{\circ} 1$ (1), fol. 90

41 A.G.S.: Consejo Real, legs. 11 y 77, Cámara de Castilla, Pueblos, leg. 14.

12 MONTERo TeJADA, Rosa Maria: Nobleza y saciedad en Castilla. El linaje Manrique (siglos XIV. XVI), Madrid, 1996, p. 140

Hispania, I.X/2, núm. 205 (2000) 425-452 
şipales de la dicba çibdad de Najera", se había encargado de proveer la carnicería de Nájera y un primo suyo, Diego de Belorado, había hecho lo mismo con respecto a la tienda del pescado 43 . Tanto Alonso como sus hijos Pedro, Alonso y Antonio de Belorado habían desempeñado regidurías en la ciudad por parte del "estado" de los ciudadanos-ruanos. Una tradición que continuará el licenciado Belorado, hijo de Pedro de Belorado "que el dicho liçençiado Velorado y el dicho Pedro de Velorado su padre y el dicho Alonso Gonçales de Velorado su abuelo fueron nonbrados por tales regidores del dicbo estado de los çiudadanos» ${ }^{44}$. Además, Alonso González de Belorado había mantenido buenas relaciones con Pedro Manrique, señor de la villa, sirviéndole en la guerra con dos escuderos con sus armas y caballos, y recibiendo acostamiento por ello: «tenia sus caballos y escuderos en su casa y mucbos criados en su casa que le serbian y aconpanaban, y a la sazon llebaban sueldo y acostamiento del duque don Pedro como bombre de armas y tenia su escudero que serbia por el a cabsa de ser el pesado y le bio tener dos escuderos que el uno se llamaba Aģofra y el otro Ceniçera» ${ }^{45}$. Podemos ver cómo algunos de estos representantes de los ciudadanos-ruanos tratan de imitar el modelo de vida de los caballeros, aunque los Belorado no conseguirán acceder al «estado" hidalgo como posiblemente fuera su intención, permaneciendo por el contrario en el «estado» ciudadano-ruano en la primera mitad del siglo XVI ${ }^{46}$.

Finalmente, el resto de los pecheros de la ciudad se integraban en el «estado" de los labradores, grupo conformado esencialmente por vecinos dedicados al trabajo directo de la tierra, aunque como clarifican algunos testigos de este sector social a mediados del siglo XVI, no todos los integrantes de este «estado" gozaban del mismo nivel socio-económico. En efecto, no todos ellos trabajaban en labores agrícolas y ganaderas, y entre sus miembros también había vecinos que se habían enriquecido y contaban con una preparación intelectual: «el ser labrador no se entiende por labranza del campo, porque muchos labradores son ofiziales y otros personas ricas y letrados que no labran, pero no por ello son dexados de nonbrar por labradores» ${ }^{47}$.

Los tres «estados» estaban representados en el concejo de la ciudad a finales de la Edad Media, aunque con una supremacía de los ciudadanos-ruanos. En

43 A.R.CH.V.: Pleitos Civiles, escribanía de A. Rodríguez (F), C. 1020-1.

at libidem.

4s Ibidem.

46 Un claro ejemplo de integración de familias de mercaderes y de hombres de negocio poderosos en el seno de la élite hidalga privilegiada, imirando la forma de vida de la nobleza feudal castellana, se constata en la ciudad de Burgos (VALDEón BaRUQUE, Julio (Director): Burgos en la Edad Media, «La segunda mitad del siglo XIV y el siglo XV” (BonACHÍA HernanDO, Juan Antonio y CASADO ALONSO, Hilario, Autores), Valladolid, 1984, especialmente, pp. 365-369). También en la ciudad de Palencia (Esteban Recio, Matía Asunción y IZQuierdo García, María Jesús: «Familias «burguesas" representativas de la élice palentina a fines de la Edad Median, Studia Histórica, $\mathrm{H}^{\mathrm{a}}$. Medieval, n' 10 (1992), pp. 101-146).

47 A.R.CH.V.: Pleitos Civiles, escribanía de F. Alonso (F), C. $1165-2$. 
efecto, los miembros de este «estado" tenían reservadas dos de las cuatro regidurías, así como dos de las cuatro juraderías de la ciudad, mientras el resto de las regidurías y juraderías se repartían a partes iguales entre los hidalgos y los labradores ${ }^{48}$. Esta posición dominante de los ciudadanos-ruanos se remontaría además en el tiempo, si hacemos caso a algunos testimonios contenidos en pleitos de mediados del siglo XVI, que hacen referencia a la existencia de un control político concejil todavía mayor por parte del estamento de los ciudadanosruanos desde tiempo atrás: «de tanto que memoria de bonbres non era en contrario la dicha ciudad de Naxara abia sido y era sienpre gobernada por solo el estado de los ruanos ciudadanos y no por otro estado alguno, $y$ caso que obiera estado de ijosdalgo seria $y$ era de algunos annos a aquella parte por conparationes y conpromisow 49 .

Según el profesor Pascual Martínez Sopena, este control social del poder urbano ya se habría producido en Nájera desde antes de mediar el siglo XII, en favor de un grupo oligárquico burgués ${ }^{50}$. No debemos olvidar en este sentido el importante impulso económico que el Camino de Santiago otorgará a los núcleos de población, que como Nájera, estaban situados a su paso, beneficiándose especialmente los vecinos dedicados a las actividades comerciales ${ }^{51}$.

DISTRIBUCIÓN SOCLAL DE LAS REGIDURIAS DE NAJERA A FINES DEL SIGLO XV

\begin{tabular}{|lll|}
\hline CIUDADANOS-RUANOS & $\longrightarrow$ & 2 REGIDURÍAS \\
HIDALGOS & $\longrightarrow$ & 1 REGIDURÍA \\
LABRADORES & $\longrightarrow$ & 1 REGIDURÍA \\
\hline
\end{tabular}

\section{NÁJERA Y EL LINAJE MANRIQUE: UNAS RELACIONES MARCADAS POR LA CONFLICTIVIDAD.}

Desde 1466, año en que el segundo conde de Treviño, Pedro Manrique, entraba por la fuerza en la ciudad reclamando el señorío sobre ella, la sociedad política local, o por lo menos una buena parte de la misma, mantendrá unas

48 "que en la dicha çiudad de Naxera en cada un anno a abido y ai un rexidor y jurado del estado de los hijosdalgo y otro rexidor y jurado del estado de los labradores christianos viejos y dos rejidores y dos jurados del estado de los ruanos» (A.R.CH.V.: Pleitos Civiles, escribania de A. Rodríguez (F), C. 1020-1).

49 A.RCH.V.: Pleitos Civiles, escribanía de F. Alonso (F), C. 1739-1. En 1456 uno de los dos alcaldes era mercader, dos de los regidores eran escribanos y uno de los jurados era hijo de un tendero (A.M.N.: L.C. 1455-56, Actas de elección de oficios insertas).

so MARTíneZ SOPENA, Pascual: «Logroño y las villas riojanas entre los siglos XI y XIV..., o.c., p. 295.

"1 RUIZ DE LA PEN̄A, Juan Ignacio: «Repoblación y sociedades urbanas en el Camino de Santiago", Actas de la XX Semana de Estudios Medievales (Estella, 1993), Pamplona, 1994, pp. 271-314. 
relaciones conflictivas con la nueva autoridad señorial. Pedro Manrique, conocido como el «duque forte», dará muestras desde los primeros momentos de un carácter violento y cruel, y no dudará en emplear el recurso a la fuerza para imponer su autoridad en la ciudad: «despues de entrado en la ciudad prendio e bizo prender muchas personas muy principales y calificadas de ella, a los cuales bizo poner en tan asperas prisiones que murieron en ellas, y a otros se les cayeron las manos con las apretadas prisiones que por largo tiempo les bizo poner y tener en las manos, $y$ otros se tullecian y perdian los pies por la misma causa...que estaba escandalizada la tierra de las fuerças que bazia, que no avia nadie que fuesse a dar quenta al rey ni a sus iusticias que no lo biziesse matar, porque con menos ocasion bazia muertes y escarmientos $\$ 32$.

La autoridad señorial desde fechas tempranas iniciará un proceso de fuerte injerencia en la ciudad, puesto de manifiesto a través de sus representantes permanentes en ella: los corregidores, que ostentaban la justicia civil y criminal así como las más altas cotas de poder ejecutivo. Entre estos representantes señoriales tenemos documentados en orden cronológico entre 1488 y 1516, al doctor Alonso Hernández de la Peña y Moneo, a Juan de Arellano, al bachiller Rodrigo de Alfaro, al licenciado Jáuregui y a Alonso de León.

Los vecinos de Nájera, atemorizados en un primer momento, no dudarán poco después en plantear sus quejas y reivindicaciones ante la justicia real. En efecto, tal y como pone de manifiesto un memorial de principios del siglo XVI, y en la medida en que las decisiones señoriales se iban haciendo cada vez más intolerables para la sociedad política local, Nájera hará saber a la autoridad real los abusos y arbitrariedades que sufrían por parte del poder señorial, con objeto de volver a integrarse nuevamente en la jurisdicción regia ${ }^{53}$. Para ello, la ciudad aprovechaba los momentos de debilidad en la posición de Pedro Manrique, como los años en los que el duque de Nájera mantuvo disputas con Fernando el Católicos4. Tal y como afirma Rosa María Montero Tejada, después de la muerte de Isabel la Católica en 1504, el primer duque de Nájera sostuvo una política de abierta confrontación con Fernando el Católico, alcanzando la tensión su momento álgido en 1507, año en el que Pedro Manrique tuvo que fortificar la ciudad de Nájera ante la llegada de Ias tropas reales a sus dominios señoriales $^{53}$. La rivalidad también afectó al monasterio de Santa María la Real, sobre el cual el duque trató de hacer encomienda, inmiscuyéndose igualmente

32 A.H.N.: NoblezA, Osuna, leg. 296, n० 1 (1), fols. 28 y 33.

"3. A.G.S.: Cámara de Castilla, Memoriales, leg. 130, doc. $n^{\circ} 61$.

s4 Sobre estas cuestiones me remito a (SUÁreZ FerNÁNDEZ, Luis y FernÁNOEZ ÁLVAREZ, Manuel: La España de los Reyes Católicos (Il), en Historia de España dirigida por Ramón Menéndez Pidal, vol. XVII, Madrid, 1978 ( $2^{2}$ edición). También proporciona daros de gran interés (MONTERO TEJADA, Rosa Maria: «Ideología y parentesco: bases de la actuación políica del primer Duque de Nájera a comienzos del siglo XVI», Espacio, Tiempo y Forma, $\mathrm{H}^{2}$. Medieval, $\mathrm{n}^{\circ} 5$ (1992), pp. 229-260).

55 MONTERo TEJADA, Rosa Maria: «Ideologia y parentesco: bases de la actuación polícica del primer Duque de Nájera..., o.c., pp. 229-260. 
en el proceso de reforma, y apoyando a los claustrales frente a los observantes que eran respaldados por Fernando el Católico ${ }^{56}$.

El clima de tensión produjo un desencadenamiento violento en los primeros años del siglo XVI. Concretamente tenemos noticias de «çierto alvoroto y levantamiento en la çibdat de Najera» a inicios del año 1515, antes del fallecimiento del primer duque de Nájera, Pedro Manriques7. La situación era propicia por la debilidad momentánea de la autoridad señorial, puesto que el duque estaba enfermo. Sin embargo, la versión de algunos vecinos afectados por la represión difiere de la versión señorial, y así Juana Jiménez afirmaba que la represión se había realizado únicamente en base a rumores que los partidarios del duque le habían transmitido: «dixeronle que algunos vesinos de Nagera y de los dichos sus barrios se querian algary.

Sea como fuere, lo cierto es que la reacción señorial no se hizo esperar. Los hijos de don Pedro, Antonio y Alvaro, apoyados por Arias Garavito ${ }^{58}$ y otros fieles vasallos entraron en la ciudad, encarcelaron a un buen número de vecinos, algunos de los cuales se refugiaron en el monasterio de Santa María la Real, y continuaron posteriormente con otras medidas represivas. Medidas especialmente duras y vejatorias si nos atenemos a las quejas presentadas por los vecinos de Nájera: «tomandonos nuestros bienes $y$ de nuestras mugeres asta los vestidos de ellas $y$ de nuestros bijos que ni les dexaron que comer ni que bestir ni en que dormir, y prendiendo algunas de ellas y echando los bijos de la çibdad" sporque todos estan presos y buidos, las casas llenas de alabarderos, tomando los vienes de las dichas casas, quitando a mi y a las otras mugeres las llabes de nuestras casas, despojandonos de quanto tenemosws9.

Los sucesos acaecidos a principios de 1515 nos permiten vislumbrar también a algunos vecinos protagonistas de los acontecimientos, como Pedro de Aguado, Baltasar de Ubago y sobre todo el bachiller Pedro del Castillo, marido de la ya mencionada Juana Jiménez, y que en años posteriores cobrarán especial protagonismo en la lucha de la ciudad para liberarse de la autoridad del linaje Manrique ${ }^{60}$.

\footnotetext{
56 Diago HERNANDO, Máximo: «El intervencionismo nobiliario en los monasterios riojanos durante la Baja Edad Media. Encomiendas y usurpaciones», Hispania, $\mathrm{n}^{\circ} 182$ (1992), pp. 811 1.861, MONTERo TejaDA, Rosa María: Nobleza y saciedod en Cassilla. El linaje Manrique..., o.c., p. 345.

${ }^{37}$ A.G.S.: Cámara de Castilla, Pueblos, leg. 14, doc. $n^{\circ}$ 66. También informa sobre estos sucesos (MONTERo TEJADA, Rosa María: «Violencia y abusos en los señoríos del linaje Manrique a fines de la Edad Media", En la España Medieval, $\mathbf{n}^{0} 20$ (1997), pp. 339-377, especialmence pp. 369-370).

58 Ésce fue uno de los vasallos más fieles del primer duque de Nájera, y desempeñó la corregiduría de la villa de Navarrete, también sefiorío del conde de Trevin̄o, entre 1495 y 1514.

59 A.G.S.: Cámara de Castilla, Pueblos, leg. 14, docs. $n^{\circ} 67$ y $\pi^{\circ} 68$.

6o También se menciona a Juan de Mungúá, Juan Gómez, Pedto de Ariz, Hernand Muñoz de Castañeda, Diego del Castillo, Juan del Castillo, Juan Domingo, Juan Ramírez, Juan de Alexos, Juan González y Martín García (A.G.S.: Cámara de Castilla, Pueblos, leg. 14, doc. $n^{0}$ 68).
} 
Las cosas no cambiaron tras la muerte de Pedro Manrique y la consiguiente llegada al poder de su hijo Antonio Manrique, segundo duque de Nájera ${ }^{61}$. Ni la recomendación que le hacía su padre en el testamento de tratar bien a sus vasallos «porque él los babía fatigado mucho por tener muchos enemigos y poco favor»62, ni los intentos de personajes como Antonio de Cardona y Francisco de Tuesta por lograr un acuerdo entre las partes, surtieron efecto. Al contrario, el nuevo duque comenzó su mandato tal y como lo había terminado Pedro Manrique, cometiendo agravios ${ }^{63}$. Por ello, a principios del año 1518 , la ciudad de Nájera envió nuevamente a dos representantes ante la justicia real para recordar al monarca el capitulado que le había sido dado en Tordesillas «sobre la libertad y agravios de la dicha çibdad y sus varrios y besinos, y porque en la tardança ay peligro, a vuestra alteza suplicamos lo mande prober brebemente conforme a justiçia» ${ }^{64}$. Así mismo pedían a la autoridad real que enviase a la ciudad a un alcalde de Corte para que hiciera juicios de residencia al corregidor y a los oficiales del concejo. Los dos procuradores enviados ante el rey eran el bachiller Pedro del Castillo y Pedro de Aguado, que como ya sabemos habían participado en los sucesos de 1515. En cuanto al capitulado de agravios, éste contenía los siguientes artículos:

1- Usurpación de la jurisdicción civil y criminal de la ciudad, su tierra y merindad, con el consiguiente desplazamiento de los alcaldes tradicionales por un corregidor.

2- Utilización arbitraria del poder y ejercicio fraudulento de la justicia por parte de los representantes señoriales, especialmente durante el mandato del corregidor Rodrigo de Alfaro "bonbre de mal bibir». Se hacía referencia a robos de dinero de la hacienda concejil, usurpación de ejidos, introducción de ganado en los baldíos, participación secreta en los negocios de abasto de carne y otros productos de primera necesidad, y reventa de grano, además de acusaciones más graves como forzar doncellas «maltratando a sus padres baçiendoles ser alcaguetes de ellas».

3- Intromisión del poder señorial en la elección de los cuatro regidores que tradicionalmente eran designados anualmente por la sociedad política local. Se hacía teferencia a que los duques habían usurpado este derecho concejil, imponiendo en las regidurías a criados suyos «algunos de

6r Pedro Manrique fue enterrado, según su deseo, en el monasterio de Santa María la Real, a pesar de la tensa relación que había mantenido con esta institución religiosa, que también puso impedimentos para su enterramiento (MONTERo TEJADA, Rosa María: Nobleza y sociedad en Castilla. El linaje Manrique..., o.c., pp. 345m346).

62 MONTERo TejaDA, Rosa María: Nobleza y saciedad en Castilla. El linaje Manrique..., o.c., p. 402.

63 «el duque no a desagrabiado, a echo agrabios de nuebo nototios, estamos destruidos, no tenemos que comer, a vuestra alteza suplicamos mande probeer brebernente con justiçia por manera que la çibdad e nosotros quedemos desagrabiados» (A.G.S.: Cámara de Castilla, Pueblos, leg. 14, do. $n^{\circ} 67$ ).

${ }^{64}$ A.G.S.: Cámara de Castilla, Mernoriales, leg. 130 , doc. $n^{\circ} 61$. 
ellos ynfames nietos degendientes por linea mascolina de bereje condenado por la santa inquisizion, los quales regidores an becho muchos males e fuerças e ynjurias a los vesinos de la dicha çibdadx. Éstos eran los responsables de las arbitrariedades cometidas en los repartos de la carga fiscal, usurpación de ejidos concejiles, quebrantamiento de privilegios y ordenanzas de la ciudad, robos de la hacienda concejil, acuerdos secretos con los abastecedores de la carnicería y de las tiendas, toma en arriendo de las rentas de propios y alcabalas de la ciudad, etc. en favor de ellos mismos y de sus parientes. Además se hacía referencia a que a los corregidores, sus tenientes y regidores, nunca se les habían hecho juicios de residencia en la ciudad.

4- Usurpación del derecho de alguacilazgo de la ciudad, cuya renta suponía anualmente mil reales. Además se acusaba a su rentero Bernal Valgañón, hijo del teniente de corregidor Juan Sánchez Valgañón, de realizar fraudes, fuerzas e incluso forzar mujeres en la cárcel.

5- Usurpación del derecho concejil de elegir escribanos públicos, imponiendo los duques en el oficio a personas no aptas para ejercer el cargo, que incluso realizaban escrituras falsas. De las misma forma, los duques también se habían apropiado de la renta procedente de la escribanía, ingresando en sus arcas veinte mil maravedís anualmente.

6- Acusación contra el corregidor Andrés Martínez de Jáuregui, de llevarse derechos excesivos de la penas impuestas, además de su salario y de ejercer como asesor, e incluso de aceptar regalos de los inculpados.

7- Concesión de privilegios señoriales a los oficiales y criados de los duques para meter su ganado en los pastos de la ciudad reservados al ganado de labor y a la carnicería, lo cual había dado lugar a una subida del precio de la carne. Se hacía especial mención al mejor pastizal de la ciudad, situado entre la fortaleza de la Mota y el Alcázar, al cual no dejaban entrar al ganado de labor de los vecinos de la ciudad, ni al ganado de los carniceros, lo que había supuesto fuertes pérdidas para los vecinos, pues el ganado entraba en las viñas y en las tierras de cereal, e igualmente había repercutido todavía más en la subida del precio de la carne. También se hacía referencia a que el duque había permitido al alcaide de la Mota, Pedro de Villodas, meter su ganado (ovejas y carneros) en las dehesas «boyadas", y así mismo los pastores del alcaide introducían el ganado en las tierras de cereal, en las viñas e incluso en las heredades cercadas, resistiéndose a los guardas de los términos y no pagando las multas.

8- Usurpación del monte y dehesa de Matarredo, y monte y dehesa de Dulçeda, de aprovechamiento público concejil. Los duques los habían talado y cortado, castigando a los vecinos que cogían el ramón que quedaba en las encinas de Matarredo para alimentar al ganado. Además habían vedado la caza en los dichos montes y dehesas, afirmándose que un vecino que había cazado dos concejos pagó veinte mil marave- 
dís de multa al duque Pedro Manrique. Los duques también habían usurpado hasta media legua del río Najerilla, que el concejo acostumbraba arrendar para pesca, con lo cual había disminuido la renta.

9- Detracción de los ingresos de la hacienda concejil por parte de la autoridad señorial. Concretamente se hacía referencia a que los duques se habían apropiado de una suma de doscientos mil maravedís, cantidad máxima que ingresaba la hacienda concejil anualmente de sus propios, e igualmente la ciudad tuvo que gastar mil reales en los lutos y para la cera de las honras por la muerte del primer duque, Pedro Manrique. También se exponía que se había utilizado dinero de la hacienda concejil para seguir pleitos en defensa de los intereses de los duques, como el pleito seguido a instancias de Pedro Manrique en Chancillería por el lugar de Bovadilla. La consecuencia de esto era que la ciudad no tenía disponibilidades de dinero para hacer frente a las reparaciones de calzadas, caminos y otros elementos urbanísticos, debiendo de realizarse repartimientos fiscales entre los vecinos pata sufragar éstos y otros gastos propiamente concejiles. Se exponía que desde hacía diez años no se tomaban cuentas a los bolseros de la situación de la hacienda concejil, lo cual estaba motivado por los muchos fraudes que se hacian.

10- Obstrucción de las obras que se realizaban en el monasterio de Santa María la Real, mediante la interposición de un pleito contra los monjes por parte del duque y de sus oficiales, cuyas costas se habían financiado con las rentas del concejo y mediante la realización de un repartimiento fiscal entre los vecinos de la ciudad.

11- Enajenación de heredades de los propios concejiles en favor de varios criados del duque Pedro Manrique. Se hacía especial mención a una huerta que había tomado en renta el concejo por seis mil maravedís anuales, $y$ que el duque la había dado a sus criados, aunque el censo seguía siendo pagado por el concejo.

12- Prohibición a los vecinos de la ciudad de vender heredades y casas sin licencia señorial, bajo castigo de perder lo vendido, e igualmente prohibición de casar a sus hijas fuera de las tierras del duque. Para esto último nunca se habían dado licencias señoriales, multándose a los vecinos que contravenían la ordenanza.

13- Aplicación de imposiciones fiscales forzosas a los vecinos, no devolviendo los eenprestidos», imponiendo sisas sobre los productos de primera necesidad sin licencia real, haciéndoles pagar las alcabalas tres y cuatro veces, y obligándoles a trabajar en las fortalezas y en otras labores señoriales, así como en las vigilancias de Nájera, Navartete y otros lugares del dominio señorial, sin darles de comer ni pagarles por ello. Igualmente se les apremiaba a contribuir en los gastos militares de los señores, obligándoles a mantener caballo y armas, y a acudir a sus guerras sin recibir paga ni acostamiento. Así mismo debian proporcionar vituallas 
(cebada, trigo y otros mantenimientos) y dar hospedaje en sus casas a las tropas señoriales de forma gratuita. Tropas que cometían todo tipo de abusos, robando, maltratando a los vecinos y deshonrando esus bijas donzellas virgenesw, sin recibir ningún castigo por ello. Todo lo cual impedía a los vecinos trabajar la tierra: "que la labrança de la dicha çibdad es perdida siendo el suelo de la dicha gibdad de lo mejor que ay en Espannaw.

14- Usurpación del ejido concejil por parte del duque Pedro Manrique para la edificación sin licencia teal del alcázar y de una torre con dos mazmorrras, en las que se recluía a los vecinos que acudían a pedir justicia. En esta torre se había encarcelado a Juan Fernández Delgadillo, Juan García, Juan Martínez de Ledesma y a otros principales de la ciudad por defender las libertades de la misma. Se hacía referencia a que Juan Martínez de Ledesma había tenido que pagar una multa de cien mil maravedís, permaneciendo en la cárcel hasta su muerte. El mismo destino esperaba a su hijo, Juan Martínez de Ledesma el mozo, que también había sido encarcelado, sufriendo grandes calamidades. Así, en el capitulado se afirmaba que las ratas le habían comido la nariz, antes de que los criados del duque lo mataran y lo sacaran arrastras por la noche, ocultando a sus familiares donde estaba sepultado. Otros vecinos de Nájera también padecieron las iras de los señores por aprocurar la libertad de la çibdad». Hernand Martínez de Flandes fue encarcelado por Pedro Manrique en la fortaleza de la villa de Navarrete, con grillos y cadenas, y sin comida hasta su muerte. Miguel Martínez y Baltasar de Ubago fueron encarcelados y torturados en las mismas mazmorras por Antonio Manrique, hasta que el poder real intervino para su excarcelación. No obstante, Miguel Martínez murió poco después a consecuencia del maltrato sufrido en la cárcel. El bachiller Pedro del Castillo y Pedro Aguado habían sufrido robos y saqueos en sus casas en 1515, no les habían permitido labrar sus viñas, y habían sido marginados en la ciudad «que ninguno fuese bosado de nos llamar sino traidores alerososs. Además al bachiller Pedro del Castillo, a pesar de ser hidalgo, no le dejaron encubar su vino en Nájera, llenaron su casa de huéspedes, utilizaron su bodega para meter el caballo del alguacil mayor y las mulas del corregidor Jáuregui, y además el señor prohibió a los vecinos de la ciudad que le contrataran como letrado. La última víctima había sido el bachiller Juan Sánchez, procurador que la ciudad pretendia enviar ante la justicia real, y que había sido encarcelado por orden del duque "y a estado y esta preso en una jaola con grillos».

15- Usurpación de los bienes de los vecinos que morían sin tener hijos, aunque sí tuvieran hermanos, sobrinos y otros parientes a quienes ceder sus propiedades.

16- Construcción sin licencia de un molino en el ejido y río público concejil, al cual el duque obligaba a llevar a moler el cereal a las panaderas de la ciudad y a los vecinos de Alesanco. 
17- Agravios cometidos contra los vecinos de la aldea de Tricio. Se afirmaba que se había obligado a los vecinos de Tricio a llevar a moler el grano a los molinos de Alonso de Barahona, fiel servidor de los duques, e igualmente se les obligaba a llevar diariamente varias cargas de paja a las caballerizas señoriales.

18- Injurias y maltratos físicos ocasionados a los vecinos de la ciudad por los criados de los duques, que incluso habían llegado a maltratar a las mujeres que no querían entregar sus gallinas a la despensa señorial. Además se había prohibido a los vecinos llevar armas en la ciudad, pero no a los escuderos y criados de los duques, lo cual incrementaba los abusos y las fuerzas de estos últimos.

19- Finalmente se hacía referencia a que los duques detraían en su favor las multas provenientes del juego, que tradicionalmente pertenecían al concejo, y así mismo habían incrementado la contribución en el tributo de la martiniega de dos mil quinientos maravedís anuales a cinco mil maravedís.

\section{EL LEVANTAMIENTO ANTISEÑORIAL DE 1520.}

La acumulación de agravios desde finales del siglo XV, y sobre todo en los primeros años del XVI, terminó por consolidar en Nájera una coyuntura mental de revuelta ${ }^{65}$, que estalló en plena efervescencia comunera, el 14 de septiembre de 1520, uel dia de la Santa Cruz a boca de noche», tal y como afirmaba un testigo ${ }^{66}$. La situación era especialmente propicia, pues Tordesillas acababa de caer en manos de la Junta Comunera, y además Antonio Mantique se encontraba en Navarra desempeñando el cargo de virrey ${ }^{67}$. Los vecinos de Nájera verán en la sublevación comunera la oportunidad esperada para desprenderse del dominio señorial, ya que entre las intenciones de los comuneros se encontraba la restitución de señoríos al patrimonio real ${ }^{68}$.

65 BARROS, Carlos: Mentalidad justiciera de los imandiños, siglo XV, Madrid, 1990, especialmente pp. 31-123. También es de gran interés sobre este tema el artículo de (GuTiÉrRez NIETO, Juan Ignacio: «Semántica del término «comunidad» antes de 1520: las asociaciones juramentadas de defensan, Hispania, $n^{\circ} 136$ (1977), pp. 319-367)

66 A.H.N.: NoblezA, Osuna, leg. 296, $\mathrm{n}^{\circ} 1$ (1), fol. 35.

67 GuTIÉRREZ NiETo, Juan Ignacio: Las comunidades como movimiento antiseñorial, Barcelona, 1973, especialmente pp. 159-164, PEREZ, Joseph: La revolución de las Comunidades de Castilla (15201521), Madrid (edición de 1979), especialmente pp. 465-466, Haliczer, Stephen: Los Comunens de Castilla: La forja de una revilución (1475-1521), Valladolid, 1987, especialmente p. 107, LORENZo CaDnrso, Pedro Luis: Los confictos populares en Castilla (siglos XVI-XVII), Madrid, 1996, especialmente pp. 78-79, Maldonado, José Ramón: «La Rioja en la Guerta de las Comunidades», Berceo (1948), pp. 283-391.

68 PÉrEz, Joseph: La revolución de lav Comunidades de Castilla..., a.c., Pp. 532-562. 
Los rebeldes de Nájera, apoyados por gentes de la comarca y de la Merindad, ocuparon las calles de la ciudad reivindicando la autoridad real y dando vivas a la «Santa Comunidad»69. Seguidamente alzaron el pendón real y procedieron a nombrar nuevos alcaldes de acuerdo con la costumbre concejil 70 . Mientras, a los partidarios y criados del duque no les quedó más remedio que refugiarse en una de las fortalezas, de donde fueron expulsados"1, saqueadas sus casas en busca de armas y mantenimientos ${ }^{72}$, y uno de ellos ahorcado por gritar consignas en favor del duque. En efecto, los testigos afirmaban que un criado del señor, un Gauna, fue ajusticiado junto a la cátcel vieja porque gritaba «viva el duque, viva el duque 73 .

Entre los cabecillas del levantamiento reconocidos por los testigos se encontraban el bachiller Juan Sanz, Pedro de Aguado y el bachiller Pedro del Castillo. Los tres habían participado con anterioridad en la defensa de los intereses de la ciudad frente a sus señores, siendo encarcelados por ello, entre otros castigos recibidos. Pedro de Aguado y Pedro del Castillo, además, habían sido los encargados de informar a la justicia real en 1518 de las arbitrariedades cometidas por los señores de la ciudad. En este sentido, y como consecuencia de sus actividades de denuncia, Pedro del Castillo se encontraba desterrado de Nájera y vivía en Santo Domingo de la Calzada ${ }^{74}$. En efecto, Francisco de Valencia, capitán de Santo Domingo de la Calzada en 1520, testificaba que había sido el propio bachiller Pedro del Castillo, quien llamando a su puerta de madrugada, le había informado de los sucesos acaecidos en Nájera, e instado a que acudiera a esta ciudad con hombres armados «pues se avia algado por la Corona Real ${ }^{75}$.

69 Entre los rebeldes llegados a Nájera se hace referencia a vecinos de Huétcanos, Urufuela, Manjarrés, Matute, Camprobín y Pedroso (A.H.N.: NoblezA, Osuna, leg. 296, $\mathrm{n}^{\circ} 1$ (1), fols. $68-$ 71 y $26\left(2^{\circ}\right.$ memorial). Un testigo, vecino de la villa de Briones, también se refería a la comunicación mantenida entre los concejos de Briones y Nájera durante el levantamiento, y cómo varios vecinos de Btiones habían acudido a prestar ayuda a los de Nájera.

70 «vio como la dicha ciudad mano armada se levanto viva el rey, viva el rey por toda la dicha ciudad, y alçaron el pendon real en nonbre de su magestad...poniendo justiçias y exercitando toda la jurisdicion en ellan (A.H.N.: NOBLEZA, Osuna, leg. 296, $\mathrm{n}^{\circ} 1$ (1), fol. 35).

7 Se hace referencia también a que los rebeldes sacaron y rompieron algunas escrituras y títulos de posesión de los duques: «fueron todos al Alcaçar donde el duque don Anconio cenia los papeles y escrituras de su mayorazgo, titulos y mercedes, $y$ anduvieron en las arcas y escritorios donde tenia los dichos titulos y mercedes y otras escrituras, y los abrieron y rompieron y sacaron de ellas lo que quisieron" (A.H.N.: NOBLEZA, Osuna, leg. 296, $\mathrm{n}^{\circ} 1$ (1), fol. 27 ( $2^{\circ} \mathrm{memorial}$ ).

72 eentraron en casa de su padre del testigo y sacaron de una sala donde tenia sus armas un coselete dorado y dos alavardas y un montante y se lo llevaron, y asi entraban en otras casas de la ciudad y tomavan atmas, mantenimientos y otras cosas" (A.H.N.: NOBLEZA, Osuna, leg. 296, $\mathrm{n}^{\circ} 1$ (1), fol. 69).

73 A.H.N.: NoBleza, Osuna, leg. $296, n^{\circ}$ I (1), fol. 36.

${ }^{4}$ A.G.S.: Patronato Real, Comunidades, caja 2, $\mathbf{n}^{\circ} 71$.

7 A.H.N.: NobiezA, Osuna, leg. 296, $n^{\circ} 1$ (1), fol. 34 . 
Los rebeldes de Nájera constituirán un cuerpo social muy heterogéneo, que agrupaba a hidalgos, ciudadanos-ruanos y labradores, pues únicamente permanecerán fieles al señor sus criados, y no todos. Ahora bien, entre los rebeldes se distinguen claramente los dirigentes ${ }^{76}$, que en su mayoría son miembros de los "principales» de la ciudad, es decir de la élite social, aunque también haya algunos representantes del "común», y el resto de la masa de insurgentes, integrada en las capas populares urbanas. Entre los dirigentes, uno de los más activos, Pedro del Castillo, era hidalgo, tenía el título de bachiller, era un importante propietario de viñedos, ejercía como letrado en Nájera y había formado parte de los regimientos de la ciudad (concretamente fue regidor en 1503) ${ }^{77}$. En este sentido una destacable característica de varios de los dirigentes es su preparación intelectual, son letrados ${ }^{78}$, aunque entre ellos también se señala a artesanos de las clases populares como un sastre y un zapatero ${ }^{79}$. Por el contrario, es la masa popular urbana la que lleva a cabo las acciones armadas y violentas, saliendo a las calles de Nájera, apresando a los criados del duque, y ejecutando a uno de ellos ${ }^{80}$.

El levantamiento de Nájera duró pocos días, pues enterado el duque de los sucesos el 15 de septiembre, partió inmediatamente hacia su ciudad con un ejército al que se sumaron tropas del condestable de Castilla y de otros linajes nobiliarios. Fallidas las propuestas de rendición realizadas a los rebeldes, y en las que según carta de Antonio Manrique habían participado como mediadores el corregidor y varios regidores de Logroño, el duque envió a un emisario a la puerta principal de la ciudad, que leyó el ultimátum señorial el 18 de septiembre. En él el duque concedía una hora de plazo a los insurrectos para deponer su actitud, amenazándoles que de no ser así ejecutaría las penas en que habían

76 «y rada la gente fazian y seguian lo que ellos mandavan y ordenavan y consejavan» (A.H.N.: NoBLEZA, Osuna, leg. $296, \mathrm{n}^{\circ} 1$ (1), fol, 67).

7 A.G.S.: Cámara de Castilla, Pueblos, leg. 14, doc. $n^{\circ} 62$ y Consejo Real, leg. 77.

78 Juan Sanz, Pedro del Castillo y el licenciado Ferrer eran letrados. Pero, además, Juan Fernández Delgadillo, Juan García, Juan Martínez de Ledesma (padre e hijo), Hernán Martinez de Flandes, Miguel Martínez o Baltasar de Ubago, que tanbién habían defendido la elibertad" de Nájera en los años anteriores a 1520 , eran igualmente letrados.

79 epreguntandole si sabia quienes fueron los principales y principio de levantarniento y rebelion de esta ciudad, dize que fueron Lope Gutierrez lofre sastre y Vergara çapatero, que era toda la confiança de los que se levantaron» (A.H.N.: NOBLEZA, Osuna, leg. 296, $\mathrm{n}^{\circ} 1$ (1), fols. 66 y 67).

${ }^{80}$ ky un Gaona allegado del duque dio vozes diziendo viva el duque viva el duque, y el comun de la ciudad que aquello vio quisieron quebrantar las puertas de la casa y le sacaron y le ahorcaron luegom (A.H.N.: NOBLEZA, Osuna, leg. 296, $\mathrm{n}^{\circ} 1$ (1), fol. 36). Sobre el papel de las clases populares urbanas en la gestación y desarrollo del movimiento comunero, pueden verse dos interesantes esrudios sobre la sociedad de Chinchilla y Toledo en el período inmediatamence anterior a las Comunidades y durante las Comunidades, respectivamente (PRETEL Marín, Aurelio: $L a *$ Comunidad y Repablicas de Cbinchilla (1488-1520). Evolución de un modelo de organización de la oposición pupular al poder patricio, Albacete, 1989, MARTÍNEZ GIL, Fernando: La ciudad inquieta. Toledo comunera, 1520-1522, Toledo, 1993). 
incurrido: muerte y pérdida de bienes ${ }^{81}$. La rendición no se produjo, y a pesar de que hubo un último intento por parte de la clerecía de la ciudad por frenar la ira señorial ${ }^{82}$, Nájera fue asaltada y saqueada por el ejército de Antonio Manrique, que apenas encontró resistencia ${ }^{k 3}$. Los principales dirigentes del alza-

${ }^{81}$ «Yo don Antonio Manrique, duque de Naxera, Conde de Trevinno, Visorey, Capitan general de la Cessaria Carholicas Magestades, de la Reyna y del Emperador su hijo, nuestros sennores, en el Reyno de Navarra y sus fronteras e comarcas. A vos los vezinos y moradores y avitantes y estantes en la mi Ciudad de Naxera, ya sabeis que es notorio en essa ciudad y en sus comarcas y en todos los Reynos de Espanna como la dicha Ciudad es mia y todos vosotros mis vassallos con la jurisdicion civil y criminal, mero misto imperio, y me pertenece por justos y derechos titulos, y la he tenido y posseydo quieta y pacificamente con todo lo que dicho es y con todas sus rentas...y vosotros cometiendo a lebe contra la fedelidad y obediencia y vasallaxe que me debeis de hecho, mano atmada faciendo sedicion en el pueblo y escandalos y rebelion, os aveis levantado y alçado contra mi y contra mi Estado y Sennorio tomando en vosotros la dicha Ciudad y la justicia de ella con dos fortaleças y me aveis quitado mis bienes y de mis criados y aveis usado de la dicha jurisdicion, y de hecho sin causa ni culpa alguna aveis aforcado a Gaona, hijodalgo, solamente porque era mi criado. Y a vuestra culpa y causa han sucedido muertes de hombres y aveis cometido otros muchos delitos como es notorio todo ello, por lo cual todo y por cada cosa de ello aveis incurrido en pena de muerte y en perdimiento de todos vuestros bienes, la qual por la notoriedad y calidad de los dichos vuestros delitos devia ser executada en vuestras personas y en los dichos vuestros bienes sin otra sentencia ni declaracion alguna como en caso notorio, permanente e inescusable, pues permaneceis en los dichos delitos, en ellos soys deprensos por mi oy dia como quiera que yo soy venido con exercito de guerra a repeler la fuerça y violençia, rebelion que me hazeis y a continuar la dicha mi possession y ha execurar las dichas penas. Pero usando de clemencia y quiedad, antes de la dicha execucion vos exorto y mando una, dos y tres vezes perentoriamente so la fidelidad y obediencia que me deveis por lo que me sois obligados, que dentro de una hota vengais y torneis a la dicha obediencia y me entregueis la dicha mi Ciudad y justicia y las dichas mis fortaleças y los dichos mis bienes y de los dichos mis criados, ca aciendo asi yo vos recibire a misericordia y me avre con vosotros venignamente, lo contratio haziendo y permaneciendo en vuestra maldad y alevosia y sedicion y violencia declarando como declaro los dichos vuestros delitos por notorios e inescusables como lo son por la presente dende agora para entonces y desde entonces para aora, vos condeno y he por condenados en las dichas penas de muerte y perdimiento de bienes, las quales con la ayuda de Dios entiendo executar y executare en vuestras personas y bienes a fuego y a sangre y repelere la dicha vuestra violencia y recobrare la dicha mi possesion...y porque de todo lo susodicho seays ciertos y no podays pretender ignorancia y si algo sucediere sera a vosotros imputado, os lo mando nocificar por este mi Trompetan (A.H.N.: NOBLEZA, Osuna, leg. 296, $\mathbf{n}^{\circ} 1$ (1), fols. 25-26 ( $2^{\circ}$ memorial).

${ }_{82}$ Varios testigos afirmaban que el abad y los monjes del monasterio de Santa María, portando el Santísimo Sacramento, salieron al encuentro del dưque y su ejército, suplicándole clemencia, pero «el dicho duque sin le querer escuchar paso adelante con toda su gente de guerra que traia en cantidad y se entro en la dicha ciudad y la saqueo" (A.H.N.: NOBLEzA, Osuna, leg. 296, $\mathbf{n}^{\circ} 1$ (1), fols. 38-39).

${ }_{33}$ «los de la çibdad lo hizieron muy mal y como onbres de poco animo que no hubo onbre que pelease, que si esco hizieran dize que se pudiera detener quanto quisieran porque avia en la dicha çibdad quatro mill onbres. La gente que traxo el duque de la que tiene en Navarra con la que vino de sus lugares y amigos de Navarra dize que serian hasta dos mill peones y dozientas lanças y quatro falconetes, estos dexo en la fortaleza de Najara. En todo este estrago no murieron sino dos personas» (Carta remitida por Juan de la Torre a la Junta de Comuneros el 25 de septiembre de 1520, A.G.S.: Patronato Real, Comunidades, caja 3, $\mathrm{n}^{\circ} 58$ ). 
miento fueron encarcelados y cuatro de ellos, Pedro del Castillo, Juan Sanz, Pedro de Aguado y un tal Botero, que había intervenido de forma directa en el ahorcamiento de Gauna, embargados sus bienes ${ }^{84}$ y condenados a morir en la horca ${ }^{85}$. El 20 de septiembre Antonio Manrique informaba a la autoridad real de la "pacificación» de Nájera y del castigo impuesto a los insurgentes ${ }^{86}$.

Nos encontramos, por tanto, ante un movimiento antiseñorial de carácter localista, de corta duración y gestado en un núcleo urbano, aunque como ya hemos visto también cuenta con la participación de gentes del entorno rural de Nájera y con la solidaridad de otros núcleos urbanos de la comarca, como Briones. Un movimiento antiseñorial muy similar a otros que se desarrollan en el territorio de la Corona de Castilla en los siglos bajomedievales ${ }^{87}$, pero que en 1520 cuenta con la peculiaridad de que tiene lugar en el contexto de la Revolución Comunera. Revolución con la que, en palabras de María Isabel del Val Valdivieso, «culmina la conflictividad urbana bajomedieval»" $\$$.

El desarrollo y finalización de los acontecimientos ocurridos en Nájera en el mes de septiembre de 1520, también guarda semejanzas con otros levantamientos antiseñoriales de este tipo. Por una lado, podemos comprobar el buen funcionamiento de la solidaridad señorial y el olvido momentáneo de las diferencias entre los linajes nobiliarios, cuando debian enfrentarse a un enemigo común ${ }^{89}$. Por otro lado, la actitud del poder real, que a pesar de las reivindica-

84 «que el dicho duque don Anconio se apodero y entro en los bienes y haziendas del bachiller Castillo y Pedro Aguado y dio y hizo merced de ellos a un Alonso Baraona su gobernador, $y$ hizo derribar la casa del bachiller Castillo y Pedro Aguado diziendo avian sido traydores». Posteriormente, tal y como afirmaba el mismo testigo, la viuda del bachiller Castillo consiguí que le fueran restituidos los bienes: «despues de apaciguadas las comunidades ocurrio a la Chancilleria de Valladolid a pedir justicia de los agravios y fuerças que el dicho duque le avia hecho en ahorcar a su marido sin causa y derriballe la casa y tomatle su hazienda, y condeno al dicho duque en la honra de su marido y de todos los bienes que le avian tornado, y traxo executoria cerca de ello y le volvieron los dichos bienes, ansi heredades como lo demas” (A.H.N.: NoBleZA, Osuna, leg. 296, $\mathrm{n}^{\circ} 1$ (1), fol. 41).

8s ahizo ahotcar quatro de los mas culpados, especialmente a un bachiller Castillo, Juan Sanz, Aguado y un Botero porque avia ahorcado por mandado de la dicha ciudad un fulano Gaona, criado del duque, $y$ el testigo los vio ahorcados en una falzeda fuera de la ciudad» (A.H.N.: NoBLEZA, Osuna, leg. 296, $\mathrm{n}^{\circ} 1$ (1), fol. 70). Un testigo afirmaba haber visto ahorcados a los cuatro uen una falzeda", y cómo una tarde que el duque pasaba por delante de los ajusticiados, se había lamentado de no haber podido ahorcar también al licenciado Ferrer, que había conseguido escapar de la represión.

${ }^{86}$ A.G.S.: Patronato Real, Comunidades, caja 2, $n^{\circ} 71$.

87 VALDEÓN BARUQUE, Julio: Los conflictos sociales en el neino de Castilla en los siglos XIV y XV, Madrid, 1975 y «Conflictos sociales en el mundo feudal hispánico», Actas del I Congresa de Estudios Medievales: En tomo al Feudalismo Hispánico, Ávila, 1989, pp. 43-55.

${ }^{96}$ VAL Valdivieso, María Isabel del: «Aspiraciones y actitudes socio-políticas. Una aproximación a la sociedad urbana de la Castilla bajomedieval", La Ciudad Medieval (BonACHÍA HERNANDo, Juan Antonio, Coord.), Valladolid, 1996, pp. 213-254, especialmente p. 250.

99 VALDEÓN BARUQUE, Julio: Los conflictos sociales en el reino de Castilla en los siglos XIV y XV..., o.f., especialmente p. 109. En el territorio altorriojano los linajes Manrique y Velasco, continuamenze enemistados, no dudarán en ayudarse mutuamente para contener la agitación que se desarrolla 
ciones de la autoridad real por parte de los insurgentes, toma partido por el poder señorial y respalda el castigo impuesto a los insurgentes que habían osado alterar el orden establecido ${ }^{90}$.

Finalmente, carecemos de datos suficientes como para hacer una valoración clara sobre las causas de la escasa resistencia puesta por los rebeldes a las tropas señoriales. Es cierto que los sublevados se enfrentaban a un ejército profesional bien pertrechado, pero por algunos testimonios también parece deducirse que no todos los vecinos de Nájera participaban con igual entusiasmo en la revuelta, existiendo diferencias entre ellos. En efecto, no todos los vecinos habían apoyado con igual fervor el levantamiento. Así, por algunos testimonios sabemos que algunos "principales" como Pedro de Ariz, que había intervenido en los sucesos de 1515, se había escondido en el momento del alzamiento, e incluso Álvaro de Porras se había negado a aceptar la alcaldía de la ciudad de mano de los insurgentes ${ }^{91}$.

\section{EVOLUCIÓN SOCIAL E INSTTTUCIONAL DEL CONCEJO DE NÁJERA EN LA PRUMERA MITAD DEL SIGLO XVI.}

El asalto y saqueo de Nájera por parte de las tropas de Antonio Manrique ocasionó graves consecuencias a la ciudad ${ }^{92} \mathrm{y}$, así, el emisario de la Junta Comunera, Juan de la Torre, se hacía eco de los setenta mil ducados que según los vecinos de Nájera costaría reparar los daños causados por el ejército señorial93. Por otro lado, los cabecillas rebeldes que habían huido escapando de la represión, no regresarán a Nájera hasta la concesión del Perdón general de 152294. Perdón del que fueron "exceptuados» o excluidos tres vecinos de la ciudad: Juan de la Bastida, Juan de Losa y Juan González. Varios testigos afirmaban que los tres habían sido «principales inventores de la rebelion» junto a los vecinos ya ajusticiados en el mes de septiembre de $1520^{95}$.

\footnotetext{
en estos momentos en sus señoríos (GUTírRRZ NIETo, Juan Ignacio: Las comunidades como movimiento antiseñorial..., o.c., pp. 159-164).

9o VALDEÓN BARUQUE, Julio: Los conflictos saciales en el reino de Castilla en los siglos XIV y XV..., o.c., especialmente p. 109.

91 "Alvaro de Porras alcalde, tomo la vara y dixo que no la queria al tiempo que se la davan, el qual oyo dezir que dixo el bachiller Castillo que anduviesse derecho, si no que jurava a Dios que haria justiçia de el» (A.H.N.: NOBLEZA, Osuna, leg. 296, $\mathrm{n}^{\circ} 1$ (1), fol. 67).

${ }_{92}$ Del saqueo de la ciudad no se libraron ni las casas de los criados del duque. Así, el restigo Juan de Salinas afirmaba que encre las casas que saquearon fue una la de su padre del testigo, aunque era criado del duque» (A.H.N.: NoBlezA, Osuna, leg. 296, $\mathrm{n}^{\circ} 1$ (1), fol. 69).

${ }_{93}$ A.G.S.: Patronato Real, Comunidades, caja 3, $\mathrm{n}^{\circ} 58$. p. 594 .

94 PéreZ, Joseph: La revolución de las Comunidades de Castilla..., o.c., pp. 585-595, especialmente
}

${ }^{95}$ A.H.N.: NoblezA, Osuna, leg. 296, n 1 (1), fols. 67-71. 
La "pacificación" de Nájera trajo consigo una reafirmación de la autoridad señorial y un aumento de la presión sobre los vasallos ${ }^{96}$, reincorporándose nuevamente el corregidor, y siendo la autoridad señorial la encargada de "proveer" los oficios concejiles ${ }^{97}$. Pero, no por ello abandonó el concejo de la ciudad la defensa de sus «derechos" $y$ «libertades» frente al poder señorial. Por el contrario, volverá a plantear nuevamente sus reivindicaciones ante los tribunales reales, tal y como lo atestiguan varios pleitos de la segunda mitad del siglo XVI8.

En lo referente al cuadro de cargos concejiles de la ciudad, la principal novedad se producirá en 1540, año en el que se introdujo el oficio de diputado, que se convertirá en el cargo concejil más importantes después de las regidurías, según la jerarquía de oficios municipales. En número de cuatro, ejercían el cargo de diputado los regidores cesantes, y por tanto los tres estamentos de la ciudad estaban representados en él en la misma medida que en las regidurías y en las juraderías. Según el Acta de elección de oficios de este año de 1540, el esquema de cargos concejiles de Nájera estaba conformado por los siguientes oficios: regidores (cuatro), diputados (cuatro), letrado, procurador, escribano de cámara, mayordomo de San Lázaro, alcaldes de Hermandad (dos), bolsero, cuadrilleros (dos), fieles de la balanza (dos), fieles del vino (dos), fieles de la carnicería (dos), veedores de los paños (dos), veedores de los zapatos (dos), veedores del campo (dos), jurados (cuatro), custieros (siete) y portazgueros (dos)99. El número de los diputados aumentará a seis en 1557, tras petición del concejo a la autoridad señorial ${ }^{100}$.

En cuanto a la sociedad política local, la documentación nos pone de manifiesto la existencia de conflictos entre los «estados» de labradores y ciudadanosruanos. En este sentido, una de las principales bazas que utilizarán los labradores para desacreditar a los ciudadanos-ruanos, se basará en la acusación de ser descendientes de judeoconversos: «que aquellas personas que an tenido y tienen y nonbran

9 LORenzo Cadarso, Pedro Luis: Los conflictos populares en Cartilla (siglos XVI-XVII)..., o.c., pp. $78-79$.

${ }^{97}$ Según testimonios contenidos en el pleito de Nájera contra los duques, estos últimos nombraban y confirmaban a los oficiales del concejo, por lo menos desde 1516. El mecanismo era el siguiente: el concejo enviaba al señor un listado con dos candidatos para cada oficio, de los cuales el señor elegía y confirmaba a uno de ellos (A.H.N.: NoBlEzA, Osuna, leg. 296, $\mathrm{n}^{\circ} 1$ (1), fol. 98). Tras el fracaso del levantamiento contra el duque, el procedimiento de designación señorial volvió a ponerse en práctica, y así lo podemos confirmar a través de las Actas de elección de oficios de la primera mitad del siglo XVI: «los oficios de este presente anno que fueron nombrados y confirmados por el duques (A.RCH.V.: Pleitos Civiles, escribanía de F. Alonso (F), C. 1738-1, Acta de elección de oficios de 1539).

98 A.H.N.: NOBlezA, Osuna, leg. $296, \mathrm{n}^{\circ}$ I (1) y CONSEjos, leg. 33.829, también proporciona datos (LORENZo CADARSO, Pedro Luis: Los conflictos populares en Castilla (siglos XVI-XVHI)..., o.c.).

99 A.R.CH.V.: Pleitos Civiles, escribanía de F. Alonso (F), C. 1738-1.

100 «atento que vosotros me lo pedis por el bien y utilidad y buena governacion de esa çiudad, nombro por diputados de mas de los suso dichos a Vernardino Urtado, Pedro Manuel Palomeque, Alonso el Rubio y Martin Romero, los quales tengan boto y asienro despues de los rexidores» (A.R.CH.V.: Pleitos Civiles, escribanía de F. Alonso (F), C. 1738-1). 
por ruanos, por otro nonbre los an tenido y tienen y reputan por conversos decendientes de judios christianos nuebos y nuebamente convertidos a nuestra santa fe catolica» 101.

En el año 1549 tenemos constancia del desarrollo de un pleito entre los ciudadanos-ruanos y los labradores por la preeminencia jerárquica durante el desarrollo de las sesiones concejiles. Según esta jerarquía, a los hidalgos les cotrespondía el primer lugar en el asiento, firma, voz y votaciones del concejo, pero con respecto al segundo lugar la cuestión no estaba tan clara, por lo menos en estas fechas de inicios de la Edad Moderna. De este forma, los labradores reclamaton su derecho al segundo lugar, que afirmaban corresponderles, forzando un pleito con los ciudadanos-ruanos. La sentencia, dictada en enero de 1550 y confirmada en noviembre de 1551, fue favorable a los labradores, a pesar de que los ciudadanos-ruanos apelaron reiteradamente a la posición de privilegio que siempre habían tenido en el concejo desde tiempo inmemorial, y que únicamente se había modificado por un compromiso realizado con los hidalgos: «por el qual dicho conpromiso se declarava que los bixosdalgo tubiesen primera boz, firma, voto y asiento en ayuntamiento y se prefiriesen a los ruanos, $y$ que despues de los dichos bixosdalgo los dichos ruanos sus partes tubiesen el segundo voto, boz, firma y asiento. Lo qual se abia siempre usado sin contradiçion alguna como se probaria... y despues de lo qual biendo que el rexidor de los bijosdalgo y los dos de los ruanos no podian bacar en las cosas de poca importancia como eran las concernientes a la agricultura, establecieron que del estado de los labradores enbiasen cada un anno un rexidor solo el qual fuese el postrero en firmar, botar y ablar, y que tubiese el mas infimo lugar y asiento en el ayuntamientom ${ }^{102}$. Sin embargo, la existencia de conversos en las filas de los ciudadanos-ruanos debió pesar más en el dictamen de los jueces, de tal manera que fueron los labradores los que consiguieron situarse en el segundo lugar de la jerarquía interna del concejo ${ }^{103}$.

${ }^{101}$ A.R.CH.V.: Pleitos Civiles, escribanía de A. Rodríguez (F), C. 1020-1. Sobre los judíos y la judería de Najera, que alcanzó un gran esplendor en el siglo XIII y primera mitad del XIV, me remito a (CANTERA MONTENEgro, Entique: Las juderias de la dioceris de Calahorra en la Baja Edad Media, Logroño, 1987, pp. 446-465).

102 A.R.CH.V.: Pleitos Civiles, escribanía de F. Alonso (F), C. 1739-1.

103 Los labradores hicieron saber el dictamen de la sentencia al corregidor y al concejo de Nájeta en el mes de diciembre de 1551 (A.R.CH.V.: Pleitos Civiles, escribanía de F. Alonso (F), C. 1739-1). Sobre la presencia de conversos en los cargos concejiles en el siglo XV puede verse el trabajo de (MÁrqueZ VILlanUeva, F.: "Conversos y cargos concejiles en el siglo XV", Revista de Archivos, Bibliotecas y Museos, $\mathrm{n}^{\circ} 63$ (1957), pP. 503-540). También pueden consultarse los trabajos de (RuCQuoI, Adeline: Valladolid en la Edad Media (el mundo abreviado, vol. $n^{\circ}$ II), Valladolid, 1987, pp. 209-213, MolÉnAT, Jean Pierre: «L'oligarchie municipale de Tolède au XV siècle», Actes du colloque organise par la Junta de Comunidades de Castilla La Mancba et la Casa de Velázquez: Tolede et lexpansion urbaine en Espagne (1450-1650), Madrid, 1991, pp. 159-177, Diago HeRnANDO, Máximo: Estructuras de poder en Soria a fines de la Edad Media, Valladolid, 1993, pp. 195-197, GuERRERO NAVARRETE, Yolanda y SÁNCHEZ BENITO, José María: Cuenca en la Baja Edad Media: un sistema de pader, Cuenca, 1994, especialmente pp. 136-155, LORENZO CADARSO, Pedro Luis: «Esplendor y decadencia de las oligarquías conversas de Cuenca y Guadalajara (siglos XV y XVI)», 
Sin duda, el «estado» de los labradores había experimentado una importante evolución desde sus orígenes, estando presentes en él a fines de la Edad Media e inicios de la Edad Moderna, vecinos que se habían enriquecido, que habían alcanzado prestigio social, y que por lo tanto aspiraban a relegar a los ciudadanos-ruanos de la posición privilegiada que todavía mantenían en el concejo ${ }^{104}$. Para ello, contaban además con un requisito fundamental que no se cansaban de reivindicar: eran los herederos de los pecheros cristianos viejos de Nájera, frente a los otros pecheros (los ciudadanos-ruanos), por cuyas venas corría sangre judía. Los ciudadanos-ruanos se encontraban, por tanto, bajo sospecha, y la pertenencia a este estamento podía acarrear serios inconvenientes para ascender socialmente ${ }^{105}$. Por ello, a través de varios pleitos contenidos en el Archivo de la Real Chancillería de Valladolid, podemos comprobar cómo algunos vecinos de Nájera, considerados ciudadanos-ruanos, tratan de probar su limpieza de sangre, mientras otros intentan demostrar su pertenencia al «estado» de los labradores, rechazando ser elegidos regidores o diputados por el «estado» de los ciudadanos-ruanos ${ }^{106}$.

Esta evolución de la sociedad política local que observamos en Nájera, guarda un cierto paralelismo con lo que ocurre en Logroño. En efecto, en esta ciudad riojana, desde los años finales del siglo XV e inicios del XVI, los estamentos de hidalgos y labradores pugnan con el estamento de los ciudadanos, $y$ progresivamente le van restando cotas de poder, hasta que hacia mediados del siglo XVI (concretamente en 1560), se llegará a una concordia por la que, entre otras cuestiones, los estamentos de labradores y ciudadanos quedaban unificados en un único estamento de pecheros, aunque los primeros rechazarán en principio la concordia apelando a su condición de slabradores cristianos viejos». Lo cierto es que en Logroño se produjo esta unificación, si bien es cierto que en

Hispania, $\mathrm{n}^{\circ} 186$ (1994), pp. 53-94, CABRERA SÁNCHEZ, Margarita: Nobleza, oligarquía y poder en Córdoba al final de la Edad Media, Córdoba, 1998, pp. I49-152).

${ }^{104}$ Así lo pudimos comprobar en líneas anteriores.

10s Sobre la actuación del Tribunal de la Inquisición en la jurisdicción de Calahorra-Logroño en el siglo XVI, me remito a (REGUERA, Iñaki: «La Inquisición: su institucionalización y su relevancia socialm, en Religiosidad y sociedad en el Pá́s Vasco (s. XIV-XVI) (GARCí FERNÁndeZ, Ernesto, Director), Bilbao, 1994, pp. 147-179).

106 En 1551 los vecinos Pedro de Calahorra, Francisco de Calahorra, Juanes de Calahorra y Alonso de Calahorra, elegidos para ocupar oficios de ciudadanos-ruanos, rechazaron los nombramientos, alegando su pertenencia al estado de los labradores, que tuvieron que probar en la Chancillería de Valladolid (A.R.CH.V.: Pleitos Civiles, escribanía de F. Alonso (F), C. 1165-2). En 1556 el licenciado Belorado se encontraba probando en la Chancillería de Valladolid la "limpieza de su filiación y descendencias (A.R.CH.V.: Pleitos Civiles, escribanía de A. Rodríguez (F), C. 1020-1). Sobre la utilización de los estatucos de limpieza de sangre como filtro para el ascenso social, me remito al trabajo de (LOREnZo CADARSO, Pedro Luis: Los conflictos populares en Castilla (siglas XVI$X V H) \ldots$, o.c., pp. 120-124). 
teoría los mercaderes y artesanos no podrían ser elegidos regidores ni electores por el «estado» de los hombres buenos pecheros ${ }^{107}$.

En Nájera desconocemos si tuvo lugar algún acuerdo similar, aunque por algunos testimonios parece vislumbrarse también una integración de los ciudadanos-ruanos que no habían conseguido acceder al «estado" hidalgo, en el «estado» de los labradores. En efecto, en 1555 constatamos la reducción del número de regidores a dos, y en 1557 se especificaba que de los dos regidores uno representaría a los hidalgos y el otro a los hombres buenos pecheros (a los que también se denomina labradores) ${ }^{108}$. Lo mismo podemos constatar en el caso de las diputaciones en 1559: tres pertenecen al «estado» de los hidalgos y las otras tres al «estado» de los hombres buenos pecheros labradores ${ }^{109}$. En definitiva, los tres «estados» en que había estado dividida la sociedad de Nájera en época medieval, habían pasado a convertirse en dos hacia mediados del siglo XVI, mediante la desaparición del «estado" que había tenido las cotas más altas de poder concejil durante la Edad Media (los ciudadanos-ruanos) y la consiguiente unificación de todos los pecheros de la ciudad en un único estamento.

DISTRIBUCIÓN SOCIAL DE LOS PRINCIPALES OFICIOS CONCEJLES DE NAJERA EN 1559

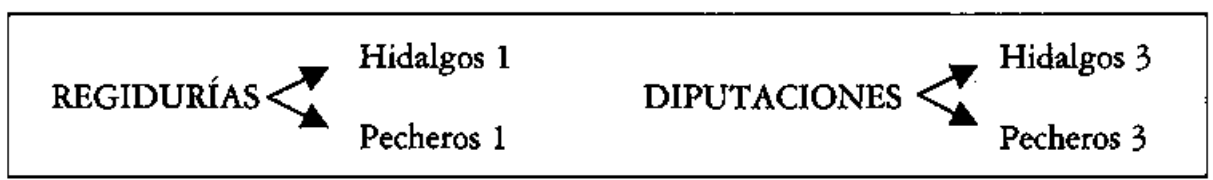

107 BaÑulelos MARTíneZ, José María: El concejo logroñés en los siglos de oro, Logroño, 1987, pp. 39-41, Burgos Esteban, Francisco Marcos: Los lazos del pader. Obligaciones y parentesco en una élite local castellana en los siglos XVI y XVII, Valladolid, 1994, especialmente pp. 76-86 y MARTíNEZ NAvaS, Isabel: «Elecciones de oficios en la ciudad de Logroño en la Edad Moderna», Anuario de Historia del Derecho Español, Tomo LXVII (1997), Homenaje a Francisco Tomás y Valiente (vol. II), pp. 1249-1273, especialmente p. 1265.

${ }_{108}$ Estas decisiones son tomadas por el poder señorial, y así en 1556 el duque afirmaba haber decidido elegir dos regidores como en 1555 uy en quanto a los demas regidores reservo en mi de nombrarlos quando y como mas convenga al bien y sosiego de esta çiudad» (A.R.CH.V.: Pleitos Civiles, escribanía de F. Alonso (F), C. 1738-1).

${ }_{109}$ A.R.CH.V.: Pleitos Civiles, escribanía de F. Alonso (F), C. 1738-1. 